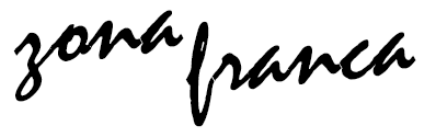

\title{
ROSE, Sonya O. (2012) ¿Qué es historia de Género?, Alianza Editorial, Madrid, 275 pp.
}

\author{
María Cristina Ockier ${ }^{*}$
}

¿Qué es historia de Género? se posiciona como una obra de lectura imprescindible para especialistas en Historia y todos aquellos que se interesen en las problemáticas de género. Es en razón de lo dicho que me sentí impulsada a escribir unas líneas acerca de un texto que, además de no ser novedoso $^{1}$, se encuentra basado principalmente en trabajos procedentes de Gran Bretaña y Norteamérica, contextualizados en los siglos XIX y XX, escenarios que parecerían algo alejados de nuestras preocupaciones más inmediatas.

Acompañado de una copiosa bibliografía, un anexo final de lecturas recomendadas que enriquece notablemente cada uno de los capítulos y un muy útil índice analítico y onomástico, Sonya $O$. Rose vuelca en este texto la solidez de su vasta trayectoria como investigadora y su prolongada experiencia como docente en el Departamento de Historia, Sociología y Estudios de la Mujer de la Universidad de Michigan.

A lo largo de sus desarrollos, de manera didáctica y accesible -sin duda, otro de sus méritos- Rose expone una serie de problemáticas que ofician de

\footnotetext{
*EIM-UNR

${ }^{1}$ De hecho, el libro fue traducido al español en 2012, lo cual haría suponer una circulación más o menos fluída en el mercado editorial hispano hablante.
}

Revista Zona Franca- Centro de estudios interdisciplinario sobre las mujeres (CEIM)- Maestría poder y sociedad desde la perspectiva de género (MG), Rosario, Argentina. ISSN, 2545-6504 http://zonafranca.unr.edu.ar/index.php/ZonaFranca| Numero 24 (2016). 
potentes disparadores a la hora de reflexionar sobre cuestiones de género, desde realidades que nos resultan más afines. A fin de corroborarlo, basta una rápida lectura de los títulos que sintetizan los contenidos que vertebran los diversos capítulos del libro: ¿Por qué historia de género?; Cuerpos y sexualidad en la Historia de género; Género y otras relaciones de diferencia; Hombres y masculinidad; Género y conocimiento histórico; Evaluar "giros" y "nuevas direcciones". A medida que avanza en la exposición, la autora nos pone en contacto con una vasta producción especializada a través de la cual pueden verse distintas perspectivas de análisis, y las controversias que generaran, en los círculos académicos, las temáticas antes mencionadas. Emerge de ello un riquísimo panorama cuyo virtuosismo no se agota en la presentación de exhaustivos trabajos que permiten comprobar la potencialidad de los estudios de género: cada uno de ellos resulta demostrativo de los múltiples derroteros, que pueden transitarse, a la hora de pensar en una investigación guiada por preocupaciones de género.

Ya desde el párrafo inicial del prefacio la autora explicita, con claridad, los propósitos y objetivos que guían la obra:

Éste es esencialmente un libro acerca de lo que hacen las historiadoras del género. No es una historia del género sino que trata de los enfoques en este campo y de su desarrollo, y toma en consideración algunos de los temas que han interesado a las historiadoras del género (Rose, 2012: 10).

Luego de aclarar que tampoco se trata de un libro de historia de las mujeres -no obstante reconocer el papel fundamental que le cupo a dicha corriente, en el desarrollo de los estudios de género- Rose expone, en el primer capítulo, algunos de los conceptos clave que jalonaron el proceso de 
consolidación de la historia de género como un campo diferenciado de investigación. Como apoyatura de la temática abordada, la autora procede a realizar una detallada exposición de los enfoques teóricos que acompañaron la construcción del concepto de género, entre los cuales destacamos -por el impacto que han tenido y siguen teniendo- los debates que suscitara la publicación, en 1986, de El Género: una categoría útil para el análisis histórico. Como es sabido, algunas de las ideas que expusiera Joan W. Scott en su célebre artículo derivaron en críticas respecto a la preocupación excesiva de su autora por el papel del lenguaje y la representación en la conformación de las identidades de género.

En el capítulo titulado Cuerpos y sexualidades en la Historia de Género, Rose recoge, de manera magistral, la densidad de los debates a los que diera lugar el concepto sexo/género. Más allá de la capital importancia que dicha distinción entrañó para los estudios de género, tal y como se la venía utilizando en algunos de ellos, se corría el riesgo de consolidar una perspectiva dicotómica que acentuaba una visión a-histórica y casi esencialista del primero de sus términos, es decir el sexo. A ello contribuyó, sin duda alguna, la sacralización de que fuera objeto la Biología, disciplina que debe ser pensada, al decir de Gisela Bock, como "una categoría sociocultural que ha marcado y distorsionado la percepción y la relación de los sexos, al mismo tiempo que la de otros grupos"(Bock, 1991: 61 y 62). En sintonía total con este punto de vista, Rose nos convoca a repensar el tema de la diferencia sexual, a fin de comprobar hasta qué punto la mayor parte de los postulados que acuñara la 
Biología, a la hora de explicar dicha diferencia, partieron en realidad de supuestos culturales. En tal sentido, menciona una serie de trabajos entre los cuales sobresalen los nombres de Thomas Laqueur y Judith Butler. El primero, por sus relevantes estudios sobre la anatomía humana y su planteo del modelo de un "único sexo" -paradigma que dominó el conocimiento científico y filosófico desde los griegos hasta Freud-:

Laqueur mostróque incluso las figuras más importantes de la revolución científica en el Renacimiento, asimilaron sus observaciones empíricas a los presupuestos políticos y culturales acerca de la similitud de los sexos. Esta visión del sexo y el cuerpo estaba de acuerdo con la idea de que las mujeres no eran sino versiones inferiores de los hombres (Rose, 2012: 51).

En cuanto a Butler, la autora destaca su idea de "performatividad", es decir, la sumatoria de acciones reiteradas que dotan al sexo de género, o también, el conjunto de los rituales culturales que resultan en que el sexo sea percibido como algo totalmente "natural"(Rose, 2012). A continuación, y en el marco de lo planteado, Rose resume diversos estudios que muestran cómo los cuerpos y la sexualidad han sido utilizados como símbolos políticos o al servicio de la nación. Entre ellos, resulta particularmente interesante -dada la vigencia del tema- el que realizara Joan W. Scott a propósito de los significados del uso del velo entre las mujeres musulmanas. Tanto en el caso de sus defensores como en el de sus detractores -quienes contraponen a dicha práctica el sistema de género francés, "considerado como superior, libre y natural"-, se trata de "un hecho que, al igual que tantos otros, revela las 
conexiones existentes entre determinadas prácticas del cuerpo y las creencias acerca de las sexualidad" (Rose, 2012: 60).

En Género y otras relaciones de diferencia, Rose aborda la complejidad de las relaciones sociales. A partir de una considerable producción historiográfica, analiza, además de las distinciones de género, las derivadas de diferencias étnicas y de clase. Como resultado, postula la existencia de una pluralidad de historias de género, siendo el contexto específico, en cada caso, lo que puede dar cuenta del ensamblaje que revistieron las aludidas diferencias en momentos dados. A fin de dar una somera idea de las diversas temáticas que aparecen a lo largo de los trabajos mencionados en este apartado, destacamos: la centralidad del cuerpo y la reproducción en el mantenimiento de la esclavitud en el Nuevo Mundo; el rol desempeñado por las distancias étnicas y culturales entre los diversos grupos de mujeres blancas, de clase media, en los movimientos filantrópicos y abolicionistas en EEUU; y el peso gravitante que le cupo a la cultura imperial entre las mujeres británicas que lucharon por reivindicaciones feministas en la India.

La existencia de desigualdades y jerarquías sociales "que se cruzan y se solapan", al decir de Rose, confluye con lo que sobre el mismo tema plantearon algunas estudiosas cuyos nombres nos resultan más familiares, como Teresita de Barbieri (2002) y Heleieth Bongiovani Saffiotti (1997). Así, luego de recordar las matrices específicas a partir de las cuales se organizan las desigualdades de género, clase y etnia (desde las diferencias corporales; desde la apropiación 
del trabajo y sus productos; y desde las diferencias culturales y raciales, respectivamente), de Barbieri concluye:

Un problema a resolver es de qué manera, en situaciones históricas concretas, estos tres ejes de distancia se articulan, entretejen e interconectan. Una primera hipótesis sostuvo el carácter acumulativo de las mismas (género+clase+etnia). Y aunque todavía aparecen algunos ecos de esta formulación, las hipótesis de trabajo más aceptadas en la actualidad hablan del carácter interactivo de dichas distancias y jerarquías, lo que supone que ciertas combinaciones pueden o bien potenciar privilegios o subordinaciones, o bien neutralizarlos (De Barbieri, 2002: 127).

Como puede verse, una vez identificados los conjuntos de distancias más relevantes que se observan en la realidad social, por medio de una operación analítica consistente en aislarlas, corresponde a la investigación determinar el modo cómo dichas diferencias se articulan en una realidad concreta y la preeminencia de alguna por sobre las restantes en momentos dados.

Bongiovani Saffioti, por su parte, destaca la interdependencia dialéctica que caracteriza a las relaciones sociales. Luego de señalar que las contradicciones de género y raza/etnia no operan aisladamente; que ellas integran, a lo largo de la historia, un verdadero nudo "con propiedades distintas de las halladas en dichos antagonismos considerados uno en uno"; y que es en dicha simbiosis que las mismas adquieren sentido, concluye: "Antes de poderem ser concebidos como constructos intelectuais [el género, la raza y la etnia, MCO], operaran na realidad empírica enquanto categorías históricas" (Bongiovani Saffioti, 1997: 2). La taxativa definición de la estudiosa brasileña interpela a algunos lectores de Joan Scott, "poco afectos a la reflexión" (Ídem), quienes dedujeron, erróneamente, de su conocidísimo artículo precedentemente mencionado, que el género aludía únicamente a una 
categoría de análisis, es decir, a una construcción intelectual. A este respecto no podemos menos que recordar aquello de "No podemos tener amor sin amantes", la bella metáfora con la cual el historiador británico Edward Palmer Thompson (2002) ilustraba la supremacía determinante de la "clase", en tanto fenómeno histórico comprobable, sobre la noción intelectual de "clase" (Prefacio a la edición de 1963).

Volviendo a Rose, el tema de la complejidad social vuelve a hacerse presente en el capítulo titulado Hombres y masculinidad. Este se inicia con un recordatorio que nos revela, una vez más, la naturalización de los discursos históricos androcéntricos: los hombres, considerados tradicionalmente como los sujetos principales de la historia, han sido vistos, al mismo tiempo, como seres incorpóreos. "Es decir, los actores históricos se han interpretado en las narrativas históricas como sujetos al margen del género" (Rose, 2012: 121). A continuación, se suceden numerosos trabajos que abordan distintos aspectos relacionados con la masculinidad: entre otros, los variables significados y códigos que históricamente se adosaron a dicho atributo; la coexistencia, en muchos casos, de representaciones opuestas en torno de lo que implicaba "ser hombre"; y la articulación entre diversos significados de la virilidad o la hombría y una variedad de tipos de regímenes de poder. Al tiempo que exploran "la vida de los hombres como actores sociales modelados por el género" (Ídem, 164), los aludidos estudios permiten constatar la omnipresencia del género a lo largo de la historia.

La variedad y diversidad de las temáticas incluidas en el capítulo Género y Conocimiento histórico constituyen una muestra incontrastable de lo que 
acabamos de decir. Allíse despliegan dimensiones del quehacer investigativo que, hasta no hace mucho, solían ser consideradas ajenas a las preocupaciones de la Historia: baste mencionar, entre muchas otras, el papel desempeñado por la sexualidad en las relaciones entre colonizados y colonizadores; la centralidad que le cupo al género en el desarrollo de la esclavitud en América y el Caribe; la imaginería de género en la construcción de la comunidad imaginada de Nación; la apelación a lenguajes de género en la conquista colonial e imperial; el rol del género en los eventos bélicos y en el proceso de construcción de las ciudadanías políticas, etc.

En síntesis. Quien frecuente este libro no sólo dispondrá de una herramienta valiosísima al momento de planificar una investigación que incluya la perspectiva de género. Todos y cada uno de sus desarrollos y recorridos conceptuales ponen en evidencia lo que hoy constituye una absoluta certeza entre quienes trabajamos en Ciencias Sociales: ninguna investigación que se precie de científica puede obviar, entre sus preocupaciones, el tratamiento de las cuestiones de género.

\section{Bibliografía}

BOCK, Gisela (1991) "La historia de las mujeres y la historia del género: aspectos de un debate internacional”, en Revista Historia Social, N 9, pp. 5577

BONGIOVANI SAFFIOTI, Heleieth (1997)“O estatuto Teórico da violência de Gènero", enRevista Zona Franca, Año V, № 6, Octubre 1997 
DE BARBIERI, Teresita (2002) "Acerca de las propuestas metodológicas feministas", en Debates en torno a una metodología feminista, Eli Bartra (compiladora), UNAM, México

SCOTT, Joan (1993) "El género: una categoría útil para el análisis histórico". En Cangiano, María Cecilia y DuBois, Lindsay (comp.)De mujer a género, Centro Editor de América Latina, Buenos Aires.

THOMPSON, Edward Palmer (1989) La formación de la clase obrera en Inglaterra, Crítica, Barcelona.

Revista Zona Franca- Centro de estudios interdisciplinario sobre las mujeres (CEIM)- Maestría poder y sociedad desde la perspectiva de género (MG), Rosario, Argentina. ISSN, 2545-6504 http://zonafranca.unr.edu.ar/index.php/ZonaFranca| Numero 24 (2016). 